ARTIGOS

\section{EMPREENDEDORISMO E EFFECTUATION: UM ESTUDO SOBRE OS EMPREENDEDORES DE SUCESSO NO SETOR DO COMÉRCIO DE FOZ DO IGUAÇU}

\section{RESUMO}

Com a temática empreendedorismo, este trabalho introduz a teoria do effectuation de Saras D. Sarasvathy, que se apresenta como uma alternativa aos modelos tradicionais de criação de negócios baseados em previsões de mercado, utilizando como ferramentas a experiência do empreendedor, sua rede de contatos e do processo de tomada de decisão em face das incertezas. Com o objetivo de descobrir evidências da utilização da lógica do effectuation pelos empreendedores de sucesso do setor do comércio de Foz do Iguaçu, este trabalho teve como metodologia a pesquisa bibliográfica e as entrevistas semiestruturadas com os fundadores de três empresas iguaçuenses: Eletromil, Empório Pomare e Districal. Os dados levantados foram analisados por meio da análise de conteúdo, o que possibilitou compreender quais empreendedores utilizaram os conceitos da teoria em estudo para criar suas empresas. Descobriu-se que existem evidências do uso da lógica do effectuation pelos empreendedores de sucesso do setor de comércio de Foz do Iguaçu, sobretudo no que diz respeito à identificação de meios e à criação de possibilidades por meio de estratégias que não consideravam previsões, na demonstração da capacidade para criar, reconhecer e descobrir oportunidades, contudo, principalmente, em suas atitudes de transformar as contingências em oportunidades valiosas e lucrativas. Além disso, identificou-se, em alguns casos, a lógica effectual ocorrendo, simultaneamente, a lógica causal.

Palavras-chave: Empreendedorismo. Effectuation. Desenvolvimento de negócios.

\section{INTRODUÇÃO}

A criação e o desenvolvimento de novos mercados e novas organizações tem sido campo de estudo de uma vertente de estudiosos, como Saras D. Sarasvathy, Professora da Darden Graduate School of Business da Universidade de Virgínia nos Estados Unidos, que é a coautora do livro "Effectuation: Elements of Entrepreneurial Expertise” de 2008. 
Sarasvathy estudou empresas norte-americanas, como a indústria hoteleira, com o propósito de compreender como os empresários criavam empreendimentos duradouros, lucrativos e de sucesso, tomando decisões em meio às incertezas da existência de mercado para seus negócios. Em seus estudos, Sarasvathy identificou que os empreendedores experientes não tomavam decisões baseados na lógica preditiva, não utilizavam pesquisas e planos, característica de um raciocínio causal. No entanto, observou que eles imaginavam diversas possibilidades para seus negócios, criando metas e objetivos com o que iam descobrindo por meio da própria experiência, das parcerias estabelecidas e da consciência dos riscos envolvidos na alocação de recursos. A essa análise ela chamou de lógica effectual, que, segundo a autora, é um processo pertencente ao indivíduo e não à empresa, e que fornece uma linha de raciocínio destoante dos processos causais, pautado na identidade do indivíduo: quem é, o que sabe e quem conhece. Seus estudos foram a base para a Teoria do Effectuation, a qual o presente trabalho estudou.

Sendo assim, este trabalho visou identificar evidências da utilização da lógica do effectuation pelos empreendedores de sucesso do setor de comércio de Foz do Iguaçu na criação de suas empresas, tendo como objetivos específicos:

a) identificar quem são os empreendedores de sucesso do setor de comércio de Foz do Iguaçu;

b) constatar como os empreendedores de sucesso selecionaram as parcerias essenciais para o desenvolvimento do negócio e;

c) definir o processo de tomada de decisão, os riscos assumidos e a seleção das oportunidades pelos empreendedores de sucesso no início da empresa.

Em face da crescente difusão do termo empreendedorismo e o surgimento mais significativo da figura do empreendedor no Brasil, principalmente devido aos incentivos gover- namentais para a formalização do trabalho, a exemplo da Lei do Microempreendedor Individual (MEI), este artigo se consolida como fonte de informação sobre empreendedorismo, uma vez que estudos sobre essa temática são escassos; além disso, contribui para o entendimento e a difusão desta nova lógica empreendedora para o desenvolvimento de negócios, reforçando as pesquisas já existentes sobre effectuation, e tornando-se ponto de partida para futuros estudos e aplicações desta teoria.

\section{REFERENCIAL TEÓRICO}

Esta seção é dividida em duas partes: a primeira como referência às principais correntes de estudos sobre empreendedorismo, conceituando e caracterizando tal fenômeno, e a segunda, o fenômeno do empreendedorismo sob a ótica da Teoria do Effectuation, conceituando a teoria, explicando seus pilares e contrastando com o modelo causal.

\subsection{EMPREENDEDORISMO}

Segundo Shane e Venkataraman (2000), o termo empreendedor é oriundo da palavra francesa entrepreneur, utilizado pela primeira vez por Richar Cantillon, um economista, em 1725 , que dizia que o empreendedor é aquele que assume risco. Contudo, algumas referências sobre os termos empreendedorismo e empreendedor são de Schumpeter (1934) que, em economia, apesar de bem aceitas e bastante utilizadas, não são as únicas, determinou o empreendedor como o provocador das mudanças econômicas, destacando-o como responsável por inovar e criar novos produtos, bem como responsável pelo crescimento econômico. Sendo assim, na visão do autor, a ação empreendedora é a que provoca mudanças econômicas, valiosas e necessárias, pois é responsável pela renovação do capitalismo por meio da destruição criativa.

Para autores como Shane e Venkatamaran (2000), empreendedorismo diz respeito à descoberta e à exploração de oportunidades 
rentáveis. É um campo que examina o que, quem e como as oportunidades empreendedoras são criadas, avaliadas e exploradas; enquanto Baron e Shane (2011, p. 6) consideram o empreendedorismo como sendo "uma área de estudo de negócios ou como uma atividade em que as pessoas se envolvem."

O empreendedor é um indivíduo dotado de sensibilidade para os negócios, possui conhecimento financeiro e é capaz de identificar e aproveitar oportunidades (CHIAVENATO, 2015). Segundo o mesmo autor, a criatividade, a energia, a imaginação e perseverança do empreendedor são aspectos que, combinados adequadamente, habilitam-no a transformar uma ideia simples em algo que produza resultados concretos e bem-sucedidos no mercado.

Dornelas (2016, p. 23) caracteriza os empreendedores como visionários, indivíduos que fazem a diferença e transformam ideias abstratas em algo concreto; sabem tomar decisões, não se sentindo inseguros com isso, sabem explorar ao máximo as oportunidades, possuem determinação e são dinâmicos, dedicados, otimistas e apaixonados pelo que fazem, assumem riscos calculados, planejam cuidadosamente cada passo de seu negócio e criam valor para a sociedade por meio de seu conhecimento e capital intelectual.

\subsubsection{O Processo Empreendedor}

Para Baron (2004 apud VIEIRA; BRITO, 2014), o que difere os empreendedores de não empreendedores é a capacidade de reconhecimento de oportunidades, sendo esta capacidade a principal característica do processo empreendedor. Para Dornelas (2016, p. 29), empreender envolve criar algo novo e de valor, cujo processo exige devoção, comprometimento, esforço e ousadia, apesar de falhas e erros.

A decisão de se tornar um empreendedor pode ocorrer por acaso, contudo fatores externos, ambientais e sociais, habilidades pessoais ou a soma de todos esses elementos influenciam o surgimento de uma nova empresa. Dornelas (2016, p. 31) diz que "o processo empreende- dor se inicia quando um evento gerador desses fatores possibilita o início de um novo negócio."

Para Baron e Shane (2011, p. 35-38), a ideia de um novo negócio está atribuída às oportunidades identificadas. Segundo os autores, existem três mudanças que podem ser consideradas como fontes de oportunidades e que são importantes para o processo empreendedor: (i) mudanças tecnológicas, que tornam possíveis novas formas de produzir; (ii) mudanças políticas e regulamentares, que promovem novos meios de utilizar os recursos existentes; e (iii) mudanças sociais e demográficas, que possibilitam a criação de novos produtos e serviços em consequência às mudanças nas preferências das pessoas.

Em complemento, Drucker (1985) diz que, dentro do empreendedorismo, existem três diferentes categorias de oportunidades: (i) a criação de novas informações, que surgem quando uma nova tecnologia é criada; (ii) a exploração das ineficiências do mercado; e (iii) da reação às mudanças nos custos e benefícios relativos ao uso alternativo dos recursos, como ocorre com as mudanças políticas, reguladores ou demográficas.

Outra vertente de estudo apresentada por Sarasvathy et al. (2003) introduz três visões sobre oportunidades empreendedoras, como demonstra o Quadro 1: 


\begin{tabular}{|l|l|}
\hline \multicolumn{2}{|c|}{ QUADRO 1 - AS TRÊS VISÕES SOBRE OPORTUNIDADE } \\
\hline \multicolumn{1}{|c|}{ Visão } & \multicolumn{1}{c|}{ Características } \\
\hline Processo de Alocação & $\begin{array}{l}\text { Reserva de recursos de forma que os fins sejam alcançados; } \\
\text { Uso do processo dedutivo para reconhecer oportunidades; } \\
\text { Foco no sistema; } \\
\text { Incerteza é gerenciada pela diversificação; } \\
\text { Sucesso é artefato estatístico. }\end{array}$ \\
\hline Processo de Descobrimento & $\begin{array}{l}\text { Correção de erros no sistema para criar novos meios para alcançar o fim; } \\
\text { Foco no processo; } \\
\text { Uso do processo indutivo para reconhecer oportunidades; } \\
\text { Incerteza é gerenciada pela experimentação; } \\
\text { Sucesso é a perda de falhas. }\end{array}$ \\
\hline Processo de Criação & $\begin{array}{l}\text { Criação de novos meios e novos fins; } \\
\text { Foco nas decisões; } \\
\text { Uso do processo de abdução para reconhecer oportunidades; } \\
\text { Incerteza é gerenciada pelo effectuation; } \\
\text { Sucesso é o consenso entre os envolvidos. }\end{array}$ \\
\hline
\end{tabular}

Quadro 1 - As três visões sobre oportunidade

Fonte: adaptado de Sarasvathy et al. (2003).

Cada uma das visões é útil conforme a situação de incerteza que se apresenta. Podem ser consideradas igualmente válidas, quando se trata de oportunidade, e são dependentes do contexto em que estão sendo analisadas. São úteis sob diferentes problemas, circunstâncias e parâmetros de decisão (SARASVATHY et al., 2003, p. 158).

Baron e Shane (2011, p. 80) dizem que "empreendedores que reconhecem oportunidades não contam somente com um melhor acesso a informações, eles também são melhores em utilizar essas informações." Segundo os autores, isso ocorre porque o conhecimento desses empreendedores é mais amplo, o que permite que interpretem e utilizem as informações obtidas de forma organizada, sendo este o mais importante elemento que possibilita a identificação de uma oportunidade.

Shane e Venkataraman (2000) expressam que a descoberta de uma oportunidade não é necessariamente uma condição para o empreendedorismo, mas sim a decisão de explorar a oportunidade, o que pode envolver a comparação do valor da oportunidade com os custos para a geração de valor. Contudo, os custos da exploração podem ser reduzidos quando o em- preendedor se utiliza de suas experiências anteriores (SHANE; VENKATARAMAN, 2000).

\subsection{A TEORIA DO EFFECTUATION}

A Teoria do Effectuation de Sarasvathy (2001a) é uma alternativa lógica ao processo de tomada de decisão sob cenários de incerteza, contrastando com os modelos tradicionais que são baseados na lógica causal (SARASVATHY, 2008). Esta lógica causal, segundo Sarasvathy (2001a), em economia, não considera a tomada de decisões sobre preços, contratação de recursos humanos, de avaliação financeira de empresas, quando a empresa ainda não existe (SARASVATHY, 2001a, p. 244).

No processo do effectuation, segundo a autora, três elementos exercem influência sobre a incerteza knightiana, a qual declara que o futuro não pode ser conhecido (KNIGHT, 1921); a ambiguidade dos objetivos; e a isotropia, que se refere ao fato de as decisões e ações que envolvem as consequências de um futuro incerto nem sempre são claras (SARASVARTHY, 2008, p. 69-70). Segundo Knight (1921), é a incerteza sobre o futuro que possibilita aos empreendedores ter lucros por meio dos dese- 
quilíbrios de mercado. Para Sarasvathy (2011, p. 1), effectuation é a resposta para as perguntas de como os empreendedores fazem para tomar decisão e agir em meio às incertezas e uma alternativa para a criação de novas empresas.

\subsubsection{Os Princípios do Effectuation}

Segundo Sarasvathy (2011, p. 2), os empresários experientes aprenderam, da maneira mais árdua, que as melhores empresas são erguidas em situações nas quais o futuro é desconhecido. Eles moldam o futuro imprevisível e desconhecido utilizando técnicas que minimizam uso de predição. Essas técnicas são os cinco princípios introduzidos por Sarasvathy (2008).

\subsubsection{Princípio do Pássaro-na-Mão}

Sarasvathy (2008, p. 74-75) diz que a estrutura do problema entre a escolha de meios para se alcançar um objetivo versus desenhar efeitos possíveis utilizando os meios disponíveis é a diferença entre o processo causal e o effectual. Os empreendedores experientes iniciam pensando primeiramente em sua identidade (quem são), seu conhecimento (o que sabem) e sua rede de contatos (quem conhecem), e, com isso, criam possibilidades com os recursos disponíveis no momento. Esses empreendedores geralmente explicam suas ações e decisões baseando-se em sua identidade em vez de suas preferências (SARASVATHY, 2008, p. 78).

\subsubsection{Princípio das Perdas Toleráveis}

Para Sarasvathy (2011, p. 2), os empreendedores de sucesso limitam seus riscos compreendendo o que estão dispostos a perder em cada etapa na criação da empresa. As perdas toleráveis não dependem dela, mas, sim, de cada indivíduo; variam entre os empreendedores e dependem também do estágio da vida em que cada indivíduo se encontra. Conhecer a condição financeira própria é a base para calcular as perdas toleráveis, além das estimativas psico- lógicas envolvidas em termos do pior cenário (SARASVATHY, 2008, p. 81).

Este princípio estabelece que o empreendedor eficaz, dentro dos meios de que dispõe, utiliza-se de sua criatividade para levar sua ideia de negócio ao mercado, isto geralmente implica a busca por parceiros. Estes parceiros, quando se comprometem com a criação da empresa, podem ou não utilizar o Princípio das Perdas Toleráveis para alocar recursos. Caso utilizem, investem somente o que estão dispostos a perder, assim como o empreendedor (SARASVATHY, 2008, p. 82).

Sarasvathy (2008, p. 88) comenta que os empresários experientes dominam o Princípio das Perdas Toleráveis, e que, com isso, reduzem os riscos, "focando no controle dos cenários desfavoráveis e na procura por meios de alcançar o mercado com o mínimo de desperdício de recursos como tempo, esforço e dinheiro." Eles combinam as perdas toleráveis com uma seleção de parceiros para criar novas oportunidades.

\subsubsection{Princípio da Colcha de Retalhos}

Os empreendedores eficazes escolhem os potenciais parceiros não baseados nos empreendimentos pré-selecionados ou nos objetivos da empresa; em vez disso, eles permitem que aqueles parceiros com compromissos reais com o negócio ajudem a dar forma à empresa. A coalescência das alianças e dos compromissos das partes reduz ou elimina as incertezas por meio de uma série de interações, formando, assim, uma rede de contatos que tende a aumentar conforme mais indivíduos se comprometam com o empreendimento. Estes stakeholders devem ser considerados nos custos de oportunidade como eventuais parceiros do negócio, podendo ou não participar futuramente da empresa.

Este princípio, combinado com a noção do Princípio do Pássaro-na-Mão, é crucial para a lógica eficaz e possui ramificações importantes para a criação simultânea de mercados e empresas. Quando combinado com o Princípio das Perdas Toleráveis, permite que o empreen- 
dedor leve sua ideia ao mercado com o mínimo de consumo de recursos de todos os envolvidos (SARASVATHY, 2008, p. 89).

\subsubsection{Princípio da Limonada}

Uma das diferenças do effectuation para os modelos causais está na exploração das contingências. Modelos causais quase sempre buscam evitar o inesperado para alcançar metas predeterminadas, encarando as contingências como erros. Em contraste, o effectuation explora as contingências, tratando eventos inesperados como oportunidades e utilizando a incerteza a favor do empreendedor (SARASVATHY, 2008, p. 89-90).

A habilidade de transformar o inesperado em um negócio valioso e lucrativo é, segundo Sarasvathy (2008, p. 90), o que se caracteriza como o cerne da experiência empresarial e o ponto central da lógica effectual. Para a autora, as empresas duradouras são, muitas vezes, resultado da exploração das contingências. O que se conquista como a estrutura, a cultura, a competência central e a sobrevivência são todos os resíduos dos envolvidos que se esforçam para forjar e satisfazer as aspirações particulares por meio das interações com as tecnologias, o espaço e tempo.

\subsubsection{Princípio do O-Piloto-no-Avião}

A lógica do Princípio de O-Piloto-No-Avião é utilizada nas áreas em que a ação humana é o fator principal na modelagem do futuro. Para Sarasvathy (2008, p. 91), a lógica do controle não preditivo procura colocar o piloto de volta no avião. Tanto a lógica causal quanto a lógica do effectuation buscam controlar o futuro; contudo, a diferença é observada no foco de cada modelo. A lógica causal foca nos aspectos previsíveis do futuro incerto, enquanto a lógica do effectuation foca nos aspectos controláveis do futuro imprevisível (SARASVATHY, 2008, p. 91). Para Sarasvathy (2008, p. 92), os empreendedores experientes lidam com a incerteza kinghtiana recusando-se a acreditar em previsões e agindo com o que possuem em mãos. Principalmente quando se trata de novos mercados e novos produtos.

\subsubsection{O Ciclo do Effectuation}

O Ciclo do Effectuation é a representação da lógica effectual na criação de produtos, mercados e empresas (SARASVATHY, 2011, p. 3). Isso porque a linha de raciocínio que leva o empreendedor à tomada de decisão é iniciada com o reconhecimento de sua identidade. A partir disso, o empreendedor identificará o que poderá fazer para tornar sua ideia realidade, pensando nos objetivos e meios de expandir recursos por meio da interação com pessoas. Esta busca por interessados em interagir com o negócio é o passo para encontrar novos parceiros que se comprometam com a ideia, possibilitando novos objetivos e novos meios. Com isso, uma rede de aliados comprometidos com a criação da nova empresa começa a surgir e o ciclo continua conforme a ideia vai tomando forma e criando mercado, aproximando o produto ou serviço da fase comercialização (SARASVATHY, 2011, p. 3). A Figura 1 ilustra o Ciclo do Effectuation.

Para os empreendedores que utilizam a lógica do effectuation, as empresas e os mercados são vistos como artefatos criados pelo homem. Raramente enxergam as oportunidades como dadas ou fora de seu controle. Segundo Sarasvathy et al. (2003), na maior parte do tempo, eles trabalham para criar, bem como reconhecer e descobrir oportunidades. Além disso, não agem como se fossem os agentes da empresa ou como fornecedores que atendem à demanda. Para eles, as empresas são uma maneira de criar uma novidade valiosa para si e para o mundo, sendo os mercados mais propensos a ser criados que descobertos.

Os stakeholders, incluindo os clientes, tornam-se parceiros na criação da empresa. Além disso, eles não buscam evitar falhas; reconhecem-nas como parte integrante do processo empreendedor. Por consequência, aprendem a sobreviver a elas, mantendo-as pequenas e matando-as logo no início, acumulando sucesso 
por meio do reforço contínuo. Para o effectuation, o sucesso ou o fracasso não são variáveis booleanas, e o sucesso e o fracasso do empreendedor não são o mesmo que o da empresa (SARASVATHY, 2008, p. 14-16). por ela é proporcional às previsões do mercado. Na lógica do effectuation, o que a empresa atinge é proporcional à quantidade e à qualidade das alianças firmadas (SARASVATHY, 2006, p. 9). O effectuation é o inverso do modelo causal,

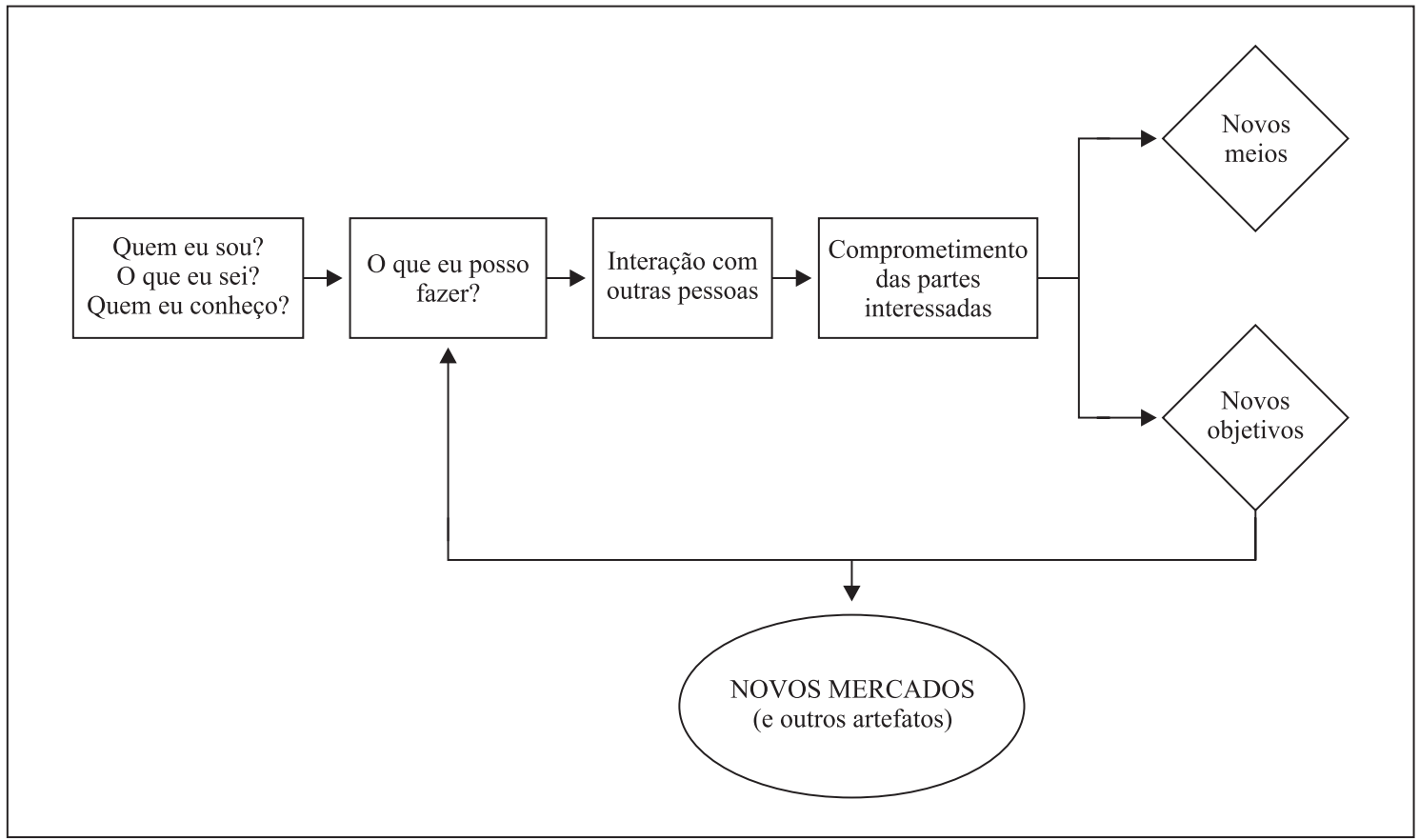

Figura 1 - Ciclo do effectuation

Fonte: adaptado de Sarasvathy (2008, p. 101, tradução do autor).

\subsubsection{Processo Causal e Effectual}

O que difere do processo causal do effectual é a escolha entre os meios existentes para alcançar um objetivo desejado. Contudo, tanto o processo causal quanto o effectual podem ocorrer simultaneamente, pois são partes integrantes do raciocínio humano (SARASVATHY, 2001a, p. 245). Os problemas causais são de decisão, úteis quando o futuro é previsível; as metas são claras, e o ambiente não depende das ações do indivíduo. Enquanto os problemas do effectuation são problemas de criação, utilizados quando não é possível conhecer o futuro, não existem objetivos claros, e o ambiente é conduzido pelas ações dos indivíduos (SARASVATHY, 2008, p. 73).

Quando a lógica causal é utilizada para criar uma nova empresa, o desempenho atingido como demonstram a Figura 2 e Figura 3.

O processo causal considerado por Sarasvathy (2001a, p. 250) como aplicável quando é preciso decidir entre o melhor, o mais rápido, o mais eficiente ou o mais econômico meio para atingir um fim desejado. Torna-se excelente para a exploração de um conhecimento, tendo como base o critério de seleção das oportunidades quanto à expectativa de retorno, enquanto o processo do effectuation explora, eficientemente, as contingências, embora o indivíduo disponha de meios específicos e escolha o efeito por suas características pessoais e sua capacidade para descobrir e utilizar as contingências. Além disso, o meio é dinâmico e não linear. 


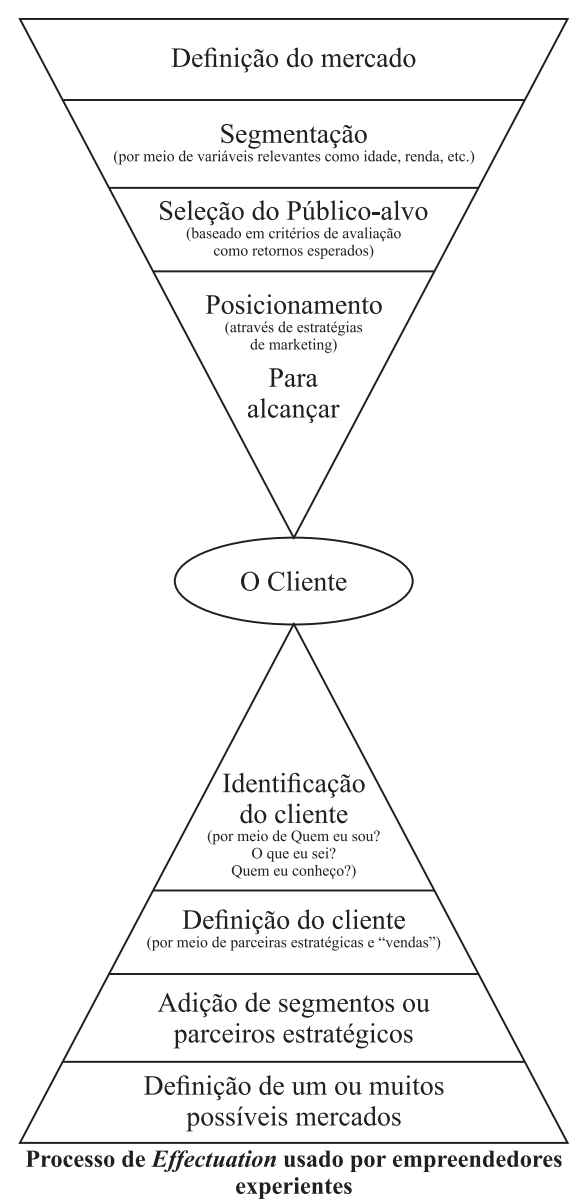

Figura 2 - Modelos de decisão: Causal e Effectual

Fonte: adaptado de Sarasvathy (2001b, p. 3, tradução do autor).

Uma decisão baseada na lógica do effectuation, segundo Sarasvathy (2001a, p. 249251), envolve um dado conjunto de meios, um conjunto de efeitos ou possíveis operacionalizações das aspirações, restrições sobre possíveis efeitos e critérios de seleção entre eles.

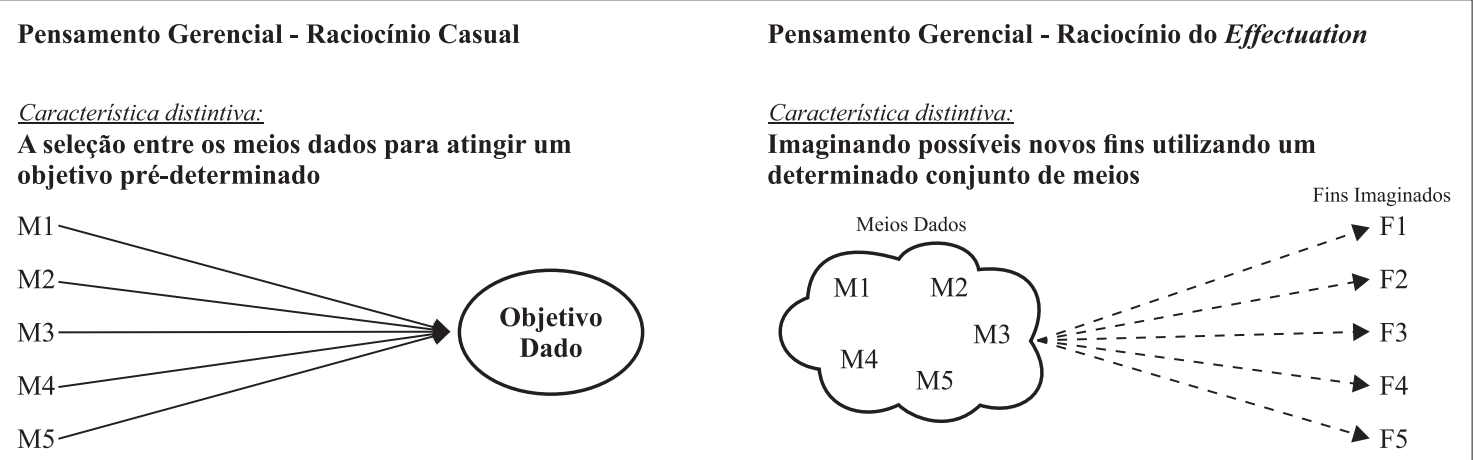

Figura 3 - Diferenciação do raciocínio causal e do raciocínio do effectuation Fonte: adaptado de Sarasvathy (2001b, p. 3, tradução do autor). 


\section{PROCEDIMENTOS METODOLÓ- GICOS}

O presente artigo tem como abordagem a pesquisa qualitativa, pois a variedade de estudos empíricos, os quais, por meio de estudos de caso, experiências pessoais, história de vida, entrevistas, observações e interações, possibilitam descrever a rotina, os momentos problemáticos e seu significado na vida dos indivíduos (DENZIN; LINCOLN, 1998, p. 3). Além disso, admitem diferentes alegações do conhecimento, métodos para coleta de dados e suas análises, o que possibilita enxergar os fenômenos holisticamente (CRESWELL, 2010, p. 187).

Quanto aos métodos de pesquisa, os mais adequados foram a pesquisa descritiva, o método dedutivo e o estudo em campo. A pesquisa descritiva permite conhecer os aspectos do comportamento humano, tanto individual quanto coletivo, tendo como foco principal o conhecimento de suas características, valores, problemas, entre outros (TRIVIÑOS, 1987, p. 111). O método dedutivo é uma argumentação que manifesta por meio de construção de estruturas lógicas, verdades particulares contidas em verdades universais (CERVO; BERVIAN; SILVA, 2007, p. 46), criando-se teorias com base em hipóteses alcançadas pelo processo de dedução lógica (ROESCH, 2013, p. 119). E o estudo de campo possibilita observar, de forma direta, as atividades do indivíduo ou do grupo (GIL, 2002, p. 53).

Os dados foram coletados por meio da pesquisa bibliográfica, que, segundo Gil (2002, p. 129) "é desenvolvida com base em material já elaborado, constituído principalmente de livros e artigos científicos", bem como referências publicadas em livros, artigos, dissertações e teses (CERVO; BERVIAN; SILVA, 2007, p. 60-61). Além disso, as entrevistas foram utilizadas para coletar informações sobre um determinado assunto diretamente com o entrevistado, buscando entender o que eles "pensam, sabem, representam, fazem e argumentam" (SEVERINO, 2013, p. 124). Entre os três tipos de entrevista (estruturada, não estruturada e painel), a mais propícia foi a entrevista não estruturada focalizada (LAKATOS; MARCONI, 2009, p. 199), que, baseada em um roteiro, proporcionava liberdade ao pesquisador para questionar o entrevistado conforme identificava como necessário (TRIVIÑOS, 1987; ANDER-EGG, 1978, p. 110 apud LAKATOS; MARCONI, 2009, p. 199).

A observação foi feita por meio da Análise de Conteúdo que, segundo (ROESCH, 2013, p. 170), classifica os procedimentos utilizados para fazer inferências a partir dos textos elaborados, os quais são muito utilizados em pesquisas científicas. Pode ser considerada como um conjunto de técnicas de análise das comunicações que descreve as informações coletadas com procedimentos sistemáticos, e que envolve a escolha dos documentos a serem analisados, a formulação de hipóteses por meio de sua leitura e a elaboração dos indicadores finais que levam à formulação da interpretação conclusiva (BARDIN, 1977). A partir das entrevistas realizadas com estes empreendedores, passa-se a fazer análises comparando com a perspectiva teórica cujo objetivo era de verificar se, no discurso do empresário, estavam presentes ou não características da teoria effectual do empreendedorismo.

As entrevistas foram analisadas por citação direta, o que possibilitou captar a emoção, os sentimentos, a experiência e as percepções básicas do entrevistado. Junto às observações feitas pelo pesquisador, permitiu-se analisar, com profundidade e detalhes, os eventos estudados, descrevendo, assim, o que aconteceu e como aconteceu com maior fidedignidade. $\mathrm{O}$ resultado foi a produção de texto, que apresentou as informações coletadas por meio dos instrumentos citados (ROESCH, 2013), além das interpretações dos dados que permitiram questionamentos por parte do pesquisador sobre as descrições feitas (GIL, 2002, p. 134).

\subsection{SUJEITO DA PESQUISA}

O critério de seleção dos sujeitos da pesquisa é baseado no julgamento pessoal do pesquisador, conforme suas habilidades e co- 
nhecimentos, característica da amostragem não probabilística por julgamento (LAMB; HAIR; MCDANIEL, 2011, p. 311). Como critério para seleção dos empreendedores, o pesquisador respeitou os seguintes itens:

a) Empreendedores com empresas constituídas em Foz do Iguaçu: as empresas deveriam estar atuantes no mercado durante a realização da pesquisa, pois não seria adequado estudar a criação de uma empresa que tenha finalizado suas operações, o que viria a conflitar com a definição de sucesso utilizada neste trabalho, definida mais adiante. Foz do Iguaçu é uma cidade do interior do estado do Paraná, com 230.000 habitantes e que tem sua economia baseada em serviços, principalmente relacionados ao turismo.

b) Empreendedores que atuem no setor do comércio: este é um dos setores com o maior número de empresários no Brasil (SEBRAE, 2015); somente no Paraná, representa 24\% dos donos do próprio negócio (SEBRAE, 2013a). Por isso, como critério para seleção de empreendedores, foi definido o setor de comércio, devido à sua representatividade na economia. Além disso, no Brasil, segundo o SEBRAE (2013b), das empresas nascidas em 2007, a taxa de sobrevivência das empresas do setor do comércio é de $77,7 \%$.

Ao selecionar os empreendedores de sucesso, não foram considerados como critérios de sucesso dados e informações obtidas por análises financeiras, uma vez que, muitas empresas relutam em passar tais informações, e devido ao tempo de execução do estudo, que não permitiria essas análises, o pesquisador definiu como critério de sucesso as empresas que estão ativas no mercado local há pelo menos 10 anos. Considerando que, no Brasil, segundo matéria publicada na Folha de São Paulo em 2015, (BOAS, 2015) metade das empresas fecham as portas após quatro anos. E por não entrarem nas estatísticas do SEBRAE e do IBGE sobre taxa de mortalidade de empresas, aquelas com mais de 10 anos de atuação podem ser consideradas de sucesso.

\section{ANÁLISE DA PESQUISA}

Foram entrevistados os fundadores das empresas Eletromil, Pomare Empório e Districal. A análise realizada contemplou pontos em comum para ambos os raciocínios, o causal e o effectual, analisando o surgimento do negócio, os riscos assumidos pelos empreendedores, as parcerias estabelecidas e a resposta às contingências, tópicos que correspondem também aos cinco princípios da teoria estudada. Por meio da análise desses tópicos, é possível compreender o processo de tomada de decisão e da criação da empresa, inferindo conforme os objetivos do artigo.

\subsection{ELETROMIL}

O primeiro empreendedor entrevistado foi Ariel Boldrini, do grupo Eletromil, composto pelas empresas Boldrini Engenharia, Eletromil e Fozmil. Com 110 funcionários, o grupo atua no mercado de construção de redes de distribuição de energia, tendo como principal cliente a Companhia Paranaense de Energia - Copel, e no comércio de materiais elétricos com a Eletromil e Fozmil. A empresa foi fundada em 1996 pelo pai de Ariel, Ademir Boldrini.

No começo do negócio, Ademir tinha como recursos o conhecimento, a experiência de anos trabalhando no ramo de distribuição elétrica, o espaço em sua casa e um veículo de pequeno porte. A ideia de abrir um negócio, segundo Ariel "foi quando a COPEL falou para ele 'Monta a empresa aí'." (BOLDRINI, 2016). O capital para abrir a empresa era próprio e de um amigo de Ademir, segundo Ariel "Ele tinha uma parte de recursos próprios, e a outra parte ele pediu emprestado para um amigo dele.’(BOLDRINI, 2016). 
A empresa sempre investiu o que podia. $\mathrm{O}$ grande investimento, como compra de maquinário, era feito somente após a assinatura do contrato com o cliente. Segundo Ariel conta na entrevista, "Todo investimento de maquinário sempre está atrelado a um contrato", "Nunca foi comprado nada por estimativa de mercado" e "Sempre por caixa próprio. A empresa ela não pega empréstimo." (BOLDRINI, 2016). Suas falas remontam o cuidado que a empresa tem para realizar despesas, o que demonstra consciência do que podem investir e até que ponto. Aqueles que estão à frente da empresa estimam investir somente o que estão dispostos para atender à demanda do mercado.

Hoje a empresa atua com empreendimentos pré-selecionados, como os contratos com a Copel, o que não é caracterizado como parte integrante do raciocínio effectual, uma vez que a teoria diz que as parcerias ajudam a moldar o negócio e o empreendimento.

Quanto à reação às contingências, é possível analisar exemplos como a reação dos empresários à alta tributação que sofriam, o que os levou a criar um grupo econômico. Segundo Ariel, o faturamento de uma empresa a coloca em um patamar elevado de tributação, e, por os empresários participarem de licitações públicas, eles precisam garantir o melhor preço, por isso criam outras empresas. "Empresa de Pequeno Porte tem vantagem de $10 \%$ em cima da de grande porte. Então, obras de até x valor, o grupo Eletromil só participa com a Fozmil, que ela é EPP.” (BOLDRINI, 2016).

Sobre o futuro da empresa, Ariel fez comentários demonstrando interesse em atuar no mercado do Paraguai. Além disso, a empresa objetiva diminuir suas operações como forma de cortar gastos “[...] a intenção é diminuir bastante" e ainda "A gente chegou no momento em que a gente vai matar cerca de $15 \%$ dela até o final desse ano." (BOLDRINI, 2016). Outro detalhe sobre a reação da empresa às contingências é caracterizado pela frase de Ariel sobre ações trabalhistas: "A gente não deixa trabalhistas crescerem. O cara entrou com uma ação, a gente chega lá e a gente já negocia para encerrar ela", (BOLDRINI, 2016). como sendo uma medida para manter o negócio da família lucrativo e valioso. Esse comportamento demonstra que, apesar de o futuro ser incerto, agem com as ferramentas que possuem em mão para controlar seu negócio e manter-se atuante.

\section{QUADRO 2 - RESUMO DAS CARACTERÍSTICAS DOS EMPREENDEDORES DA ELETROMIL PRINCÍPIO PÁSSARO-NA-MÃO \\ - Experiência no ramo; \\ - O espaço em casa e a pampa que possuía para operar.}

\section{PRINCÍPIO PERDAS TOLERÁVEIS}

- Os investimentos eram feitos somente após a assinatura dos contratos, não por estimativa de mercado;

- Consciência do que podem investir e até que ponto;

- Estimativas de investimento estão atreladas ao atendimento à demanda do mercado.

\section{PRINCÍPIO COLCHA DE RETALHOS}

- Investimento inicial foi do capital próprio e com um amigo;

- A empresa atua com empreendimentos pré-selecionados.

\section{PRINCÍPIO LIMONADA}

- A Copel forçou a empresa a crescer para atender à região de Cascavel, sob a ameaça de rescindir contratos, por isso investiram no crescimento da empresa;

- O desejo de enxugar a empresa para reduzir custos é evidente, por isso não encararam como oportunidade essa exigência do cliente, mas, para manterem-se ativos, acataram.

\section{PRINCÍPIO O-PILOTO-NO-AVIÃO}

- A opção por enxugar a estrutura e a folha de pagamento da empresa, apesar de que o futuro da Eletromil é previsível, devido aos contratos já assinados com a Copel.

Quadro 2 - Resumo das características dos empreendedores da Eletromil

Fonte: elaborado pelo autor (2016). 


\subsection{EMPÓRIO POMARE}

A segunda entrevista realizada foi com a empreendedora Michelli Cerutti, fundadora e proprietária do Empório Pomare. Fundada em 2002 com a proposta de incentivar uma vida mais saudável por meio do consumo de alimentos com qualidade, hoje é referência na cidade por sua estrutura, produtos e qualidade. Comercializa também como atacado, hortifrúti, frutos secos, alimentos funcionais, sem lactose, sem glúten, especiarias, suplementos, grãos, sucos, ervas, óleos, temperos, entre diversos outros. $\mathrm{Na}$ sede, a empresa possui o Espaço Gourmet, que oferece refeições saudáveis diariamente aos clientes Pomare. A empresa também apoia a prática de atividade física patrocinando eventos esportivos.

A experiência com a fruteira da família, o conhecimento em finanças, adquirido durante o trabalho em uma financeira, o curso de Administração, o técnico em Publicidade e Propaganda são exemplos de recursos que a empreendedora tinha em mãos, e que utilizou para iniciar o negócio.

Sua percepção sobre o que estava disposta a investir é observada por falas que demonstraram consciência de sua condição financeira, como:

[...] eu consegui a oportunidade de ter uma amiga minha investindo. Então ela que investiu na Pomare. Ela que abriu a loja né, e eu com minha experiência, porque como eu sempre trabalhei eu tinha a experiência de lidar com fornecedor e tudo mais e no começo como a Pomare ainda não me dava renda, eu trabalhei meio período fora e o restante do período dentro da loja, que daí que eu me sustentava (CERUTTI, 2016).

O início conturbado e difícil não desmotivou Michelli, que se utilizava da criatividade para criar as condições para atuar. Além disso, a empreendedora enxergava as contingências como oportunidades, e não empecilhos. Quando uma reforma repentina foi necessária, caso contrário a fachada da loja cairia, ela aproveitou para reestruturar o local e modificar a identidade visual da empresa.

No decorrer dos anos, ficou evidente na entrevista que Michelli conseguiu criar uma rede de parceiros comprometidos com a Pomare. Dois exemplos citados são a amiga sócia, que investiu no início do negócio, e a busca de recursos financeiros em bancos e agiotas, que financiaram a reforma da fachada. Além disso, ela considera os clientes e colaboradores como fundamentais para o desenvolvimento da empresa. Segundo a empresária “[...] se não fosse os meus colaboradores, se não fossem os meus clientes, a Pomare não é o que ela é hoje, não seria o que ela é hoje." (CERUTTI, 2016). Esta frase ilustra a cultura organizacional forte da Pomare, com uma equipe que veste a camisa, característica de empresas duradouras que conquistam estrutura e cultura que satisfazem as aspirações do empreendedor e garantem a sobrevivência.

Atualmente, a Pomare trabalha para valorizar cada vez mais a experiência do consumidor. A estratégia é se fragmentar sem perder a essência e atuar em novas praças, mantendo a matriz, e, com as novas lojas, atingir o público que, até então, não atingem. Como é possível concluir a partir da fala de sua proprietária: "E a ideia assim que eu sinto que o cliente valoriza muito quando a gente valoriza eles. E valorizar eles é realmente melhorar a infraestrutura, melhorar o atendimento, melhorar a experiência dele. Então é isso que a gente está querendo. A gente faz com sentimento." (CERUTTI, 2016).

Apesar de hoje ter ideia para onde quer ir, suas ações não buscam evitar incertezas e controlar o futuro por meio da previsão. Aprender fazendo é uma característica muito forte do empreendedorismo da Michelli. A intuição e o sentimento são o que guiam sua jornada em- 
preendedora, e são os elementos humanos que mantêm a Pomare atuante no mercado, recusando-se a aceitar as contingências como erros e agindo com o que possui em mãos. abrir a Districal, o empreendedor utilizou o conhecimento, suas habilidades, a rede de contatos, além da experiência com uma empresa do comércio de materiais para a construção que

\begin{tabular}{|c|}
\hline QUADRO 3 - RESUMO DAS CARACTERÍSTICAS DA EMPREENDEDORA DA POMARE \\
\hline PRINCÍPIO PÁSSARO-NA-MÃO \\
\hline $\begin{array}{l}\text { - Experiência com a fruteira da família; } \\
\text { - Conhecimento em finanças, adquirido durante o trabalho em uma financeira; } \\
\text { - Curso de Administração e técnico em Publicidade e Propaganda. }\end{array}$ \\
\hline PRINCÍPIO PERDAS TOLERÁVEIS \\
\hline $\begin{array}{l}\text { - Consciência de sua condição financeira; } \\
\text { - Uso da criatividade para fazer o negócio acontecer; } \\
\text { - Busca por parcerias que se comprometessem com os recursos financeiros necessários para iniciar o negócio. }\end{array}$ \\
\hline PRINCÍPIO COLCHA DE RETALHOS \\
\hline $\begin{array}{l}\text { - Criação de uma rede de parceiros comprometidos (investidores, bancos e agiotas), colaboradores e clientes; } \\
\text { - Consideração pelos clientes e pelos colaboradores participantes dos momentos mais importantes da Pomare. }\end{array}$ \\
\hline PRINCÍPIO LIMONADA \\
\hline $\begin{array}{l}\text { - A reforma da fachada, que oportunizou a alteração da identidade da empresa; } \\
\text { - A cultura organizacional e a participação dos colaboradores que vestem a camisa. }\end{array}$ \\
\hline PRINCÍPIO O-PILOTO-NO-AVIÃO \\
\hline $\begin{array}{l}\text { - Age pelo sentimento; } \\
\text { - Busca contato com seus clientes e colaboradores, o que possibilita a Pomare manter-se no mercado. }\end{array}$ \\
\hline
\end{tabular}

Quadro 3 - Resumo das características da empreendedora da Pomare

Fonte: elaborado pelo autor (2016).

\subsection{DISTRICAL}

O último empreendedor entrevistado foi o Paulo Fernando Quintella, fundador da Districal Materiais para Construção. Fundada em 1996, hoje, com duas sedes em Foz do Iguaçu, a empresa é a maior distribuidora de aço e ferro na cidade e região; conta com mais de oitenta colaboradores e uma frota com mais de vinte veículos que atendem ao mercado local, a região oeste, sudoeste e centro-oeste do Paraná, bem como a parte oeste do estado de Santa Catarina. Além da Districal, Quintella é proprietário da Imacofer, empresa para corte de lâmina de aço para a construção civil e também de uma construtora.

Quintella, como é conhecido no ambiente de trabalho, trabalhou toda a vida no ramo de materiais de construção: começou como auxiliar em um escritório de uma indústria de cerâmica e chegou a ser representante comercial por 15 anos. Como recursos disponíveis para faliu. Não tinha medo de investir e conhecia sua capacidade financeira; tinha noção dos recursos que possuía em mãos, porém, mais que isso, estava preparado psicologicamente para criar a empresa e correr riscos com o mínimo de desperdício de recursos possível. Duas falas demonstram essa predisposição psicológica, aprendizado obtido pelas experiências profissionais anteriores, para o empresário é preciso:

[...] sempre gastar menos do que ganha, muita perseverança, muita atitude, persistência, muito trabalho, muito empenho, sacrifício." e "Eu vivia com a rentabilidade das minhas comissões, então esse dinheiro pouco, ou um pouquinho, ou muito ia ficando pra empresa. Então foi assim que foi sendo criado um capital de giro (QUINTELLA, 2016). 
A abertura da empresa ocorreu a pedido de um fornecedor. Por anos, a Districal vendeu cal somente para o Paraguai. Depois de um tempo, começou a explorar o mercado nacional, principalmente o de Foz do Iguaçu e região, e isso demandou novas parcerias com fornecedores. Além disso, Quintella atribui o crescimento da empresa como resultado dessas parcerias e das pessoas que ele contratou, quando ele fala que muitas oportunidades o mercado the proporcionou e quando diz que o crescimento faz que se estabeleçam colaboradores que contribuam com a empresa. Esses são exemplos de parcerias que moldam o negócio e faz que a empresa conquiste mercado.

Quando a Districal se tornou distribuidora oficial da Gerdau na região, Quintella expandiu seus negócios, atendendo, assim, toda a região, montando, inclusive, uma filial em
Cascavel, empresa que optou por fechar seis anos depois. Esse é um exemplo de como o empreendedor transformou uma oportunidade em algo valioso e lucrativo. Mesmo com a filial de Cascavel fechada, a Districal ainda atende o mercado da cidade e da região, vendendo mais do que na época da filial aberta.

Apesar do conhecimento que Quintella tem, suas ações de controle são a resposta do sucesso da empresa e da atuação no mercado há 20 anos. Ele sempre teve consciência dos recursos que possuía, mas sempre buscou mais, tendo o cuidado de não comprometer a saúde do negócio. Porém, isso nunca o impediu de criar novas possibilidades para a Districal, e, com isso, tem certeza de que está preparado para o que surgir no futuro, mesmo que tenha uma expectativa sobre ele.

\section{QUADRO 4 - RESUMO DAS CARACTERÍSTICAS DO EMPREENDEDOR DA DISTRICAL PRINCÍPIO PÁSSARO-NA-MÃO}

- Possui experiência no ramo;

- Trabalhou como auxiliar em um escritório de uma indústria de cerâmica e foi representante comercial por 15 anos;

- Tem conhecimento de suas habilidades;

- Tinha contato com fornecedores e soube aproveitar o que possuia no momento para começar a empresa;

- Teve uma experiência com uma empresa do comércio de materiais para construção que faliu.

\section{PRINCÍPIO PERDAS TOLERÁVEIS}

- Não tinha medo de investir, conhecia sua capacidade financeira, tinha noção dos recursos que possuía em mãos;

- Estava preparado psicologicamente para criar a empresa e correr riscos;

- Buscava com suas ações alcançar o mercado com o mínimo de desperdício de recursos.

\section{PRINCÍPIO COLCHA DE RETALHOS}

- Explorava no início o mercado do Paraguai, posteriormente começou a explorar o mercado nacional, o que levou a estabelecer novas parcerias;

- Atribui o crescimento da empresa como resultado dessas parcerias e das pessoas que ele contratou;

- Diz que muitas oportunidades o mercado lhe proporcionou;

\section{PRINCÍPIO LIMONADA}

- Expandiu seus negócios quando se tornou distribuidor oficial da Gerdau na região, abriu, por isso, uma filial da Districal em Cascavel, que fechou seis anos depois;

- Atende o mercado local e da região, vende mais do que na época com a filial aberta.

\section{PRINCÍPIO O-PILOTO-NO-AVIÃO}

- Busca investir e crescer sem comprometer a saúde do negócio;

- Fala que é preciso gastar menos do que ganha;

- Está preparado para as novas possibilidades que possam surgir no futuro.

Quadro 4 - Resumo das características do empreendedor da Districal

Fonte: elaborado pelo autor (2016). 


\section{CONSIDERAÇÕES FINAIS}

Com base na Teoria do Effectuation, o presente estudo teve como objetivo geral compreender o processo de criação e o desenvolvimento de empresas do setor do comércio de Foz do Iguaçu, visando identificar evidências do uso da lógica do effectuation por parte dos empreendedores de sucesso na criação de suas empresas. Como resultado, por meio de entrevistas semiestruturadas com três empreendedores: Ariel Boldrini da Eletromil, empresa de varejo de materiais elétricos e prestadora de serviços de engenharia elétrica; Michelli Cerutti do Empório Pomare, estabelecimento comercial de produtos secos e molhados; e Paulo Fernando Quintella da Districal, empresa de venda de materiais de construção.

$\mathrm{O}$ que foi constado é que existem evidências da lógica do effectuation no processo de criação e desenvolvimento das três empresas do setor do comércio de Foz do Iguaçu. É válido ressaltar, segundo a teoria, e também pelo que foi observado com o desenvolvimento do estudo, que os empreendedores iniciaram seus negócios com os meios disponíveis e criaram possibilidades por meio de estratégias que não consideravam previsões, ponto característico consonante ao effectuation. Também demonstraram criar, reconhecer e descobrir oportunidades e atuaram como fatores principais das mudanças, criando empresas valiosas para si e para o mercado. Além disso, foi observado o uso da lógica causal, ocorrendo simultaneamente ao effectual, o que é evidenciado no caso da Eletromil e da Districal, que atuam em uma fração de mercado existente, desde a época da criação das empresas, e exploram um conhecimento.

$\mathrm{O}$ desenvolvimento deste estudo ocorreu em oito meses, período que se apresentou suficiente para a elaboração do plano de pesquisa e sua execução. A principal dificuldade do trabalho consiste, durante a fase de realização do contato com empreendedores locais, na falta de resposta a respeito da participação na pesquisa, o que limitou a coleta de mais dados.

Por fim, fica evidente a necessidade de novas pesquisas sobre o tema, sobretudo em língua portuguesa. Também é necessário desenvolver novas pesquisas sobre o surgimento e desenvolvimento de negócios no País, estudando, simultaneamente, o uso da lógica causal e effectual, objetivando a criação e o planejamento de novas metodologias e técnicas de desenvolvimento de negócios.

\section{ENTREPRENEURSHIP AND EFFECTUATION: A STUDY ON THE SUCCESSFUL ENTREPRENEURS OF THE COMMERCIAL SECTOR OF FOZ DO IGUAÇU}

\section{ABSTRACT}

The present paper is a study in the field of entrepreneurship, and introduces Saras D. Sarasvathy's effectuation theory, which presents itself as an alternative to the traditional models of creating new ventures, by not being based on predictions, but rather by using the entrepreneur's own expertise, network and decision-making process as tools to face uncertainties. Aiming at unearthing evidence of the use of effectuation logic by successful entrepreneurs in the commercial sector of Foz do Iguaçu, this article has a methodology of bibliographical research and semi-structured interviews with the founders of three companies - Eletromil, Empório Pomare and Districal. The data collected was analyzed by content analysis, which enabled the researcher to understand the concepts of the theory under analysis that were used by the entrepreneurs to create their companies. There is evidence of use of the effectuation logic in said companies, especially regarding the means of identifying and creating opportunities through strategies that did not consider forecasts in the demonstration to create, recognize and discover opportunities, but mainly in their attitude in viewing contingencies as valuable and lucrative opportunities. In addition, it was identified that, in some cases, effectuation logic occurred simultaneously with causal logic.

Keywords: Entrepreneurship. Effectuation. Business Development. 


\section{INICIATIVA EMPRESARIAL Y \\ EFFACTUATION: UN ESTUDIO SOBRE LOS EMPRESARIOS DE ÉXITO DEL SECTOR COMERCIAL EN FOZ DE IGUAÇU}

\section{RESUMEN}

Con una temática de iniciativa empresarial, este trabajo introduce la teoría de effectuation, de Saras D. Sarasvathy, que se presenta como una alternativa a los modelos tradicionales de creación de negocios basados en previsiones de mercado, utilizando como herramientas la experiencia del emprendedor, su red de contactos y el proceso de tomada de decisión frente a las incertitudes. Con el objetivo de descubrir evidencias de la utilización de la lógica de effectuation por los emprendedores de suceso del sector comercial de Foz do Iguaçu, este trabajo tuvo como metodología la pesquisa bibliográfica y las entrevistas semiestructuradas con los fundadores de tres empresas de Iguaçu: Eletromil, Empório Pomare y Districal. Los datos levantados fueron analizados por medio del análisis de contenido, lo que posibilitó comprender cuales de los emprendedores utilizaron los conceptos de la teoría bajo estudio para crear sus empresas. Se descubrió que existen evidencias del uso de la lógica de effectuation por los emprendedores de suceso del sector del comercio de Foz do Iguaçu, sobre todo en lo que concierne la identificación de medios y la creación de posibilidades a través de estrategias que no consideraban previsiones en la demostración de la capacidad para crear, reconocer y descubrir oportunidades, pero principalmente en su actitud en transformar las contingencias en oportunidades valiosas y rentables. Además, se identificó en algunos casos la lógica de effectuation ocurriendo simultáneamente a la lógica causal.

Palabras-clave: Iniciativa Empresarial. Effectuation. Desarrollo de Negocios.

\section{L'ESPRIT D'ENTREPRISE ET EFFECTUATION : UNE ETUDE SUR LES ENTREPRENEURS DE SUCCES DU SECTEUR COMMERCIAL A FOZ DO IGUAÇU}

\section{RESUME}

Dans la thématique de l'esprit d'entreprise, ce travail introduit la théorie de effectuation, de Saras D. Sarasvathy, qui se présente comme une alternative aux modèles tradionnels de création d'entreprises basés sur les prévisions du marchet, en utilisant comme outils l'expérience de l'entrepreneur, son réseau de contacts et le processus de prise de décision face aux incertitudes. Ayant l'objectif de découvrir des preuves de l'utilisation de la logique de effectuation par les entrepreneurs de succès du secteur commercial de Foz do Iguaçu, ce travail a eu comme méthodologie la recherche bibliographique et les entretiens semistructurés avec les fondateurs de trois entreprises : Eletromil, Empório Pomare et Districal. Les données obtenues ont été évaluées à travers de l'analyse du contenu, ce qui a permit de comprendre quels entrepreneurs ont utilisé les concept de la théorie sous étude pour créer leurs entreprises. Nous avons découvert que des preuves de l'utilisation de la logique de effectuation par les entrepreneurs de succès du secteur commercial de Foz do Iguaçu existent, surtout en ce qui concerne l'identification de moyens et la création de possibilités à travers des stratégies qui ne considéraient pas des prévisions dans la démonstration de la capacité pour créer, reconnaître et découvrir des opportunités, mais surtout dans leur attitude de transformer les difficultés en opportunités précieuses et rentables. En outre, nous avons indentifié des cas où la logique de effectuation a eu lieu simultanément à la logique causal.

Mots-clés: Esprit d'entreprise. Effectuation. Développement d'entreprises. 


\section{REFERÊNCIAS}

BARDIN, L. Análise de conteúdo. Lisboa: Edições 70, 1977.

BARON, R. A.; SHANE, S. A. Empreendedorismo: uma visão do processo. São Paulo: Cengage Learning, 2011.

BOAS, B. V. Metade das empresas fecha as portas no Brasil após quatro anos, diz IBGE. Folha de São Paulo. 2015. Disponível em: $\quad<$ http://www1.folha.uol.com.br/mercado/2015/09/1677729-metade-das-empresas-fecha-as-portas-no-brasil-apos-quatro-anos-diz-ibge.shtml>. Acesso em: 6 jun. 2016.

BOLDRINI, A. Entrevista com representante da Eletromil. Entrevista concedida a Emerson Diego Zotti. Foz do Iguaçu, 29 ago. 2016.

CERUTTI, M. Entrevista com representante da Pomare. Entrevista concedida a Emerson Diego Zotti. Foz do Iguaçu, 19 set. 2016.

CERVO, A. L.; BERVIAN, P. A.; SILVA, R. da. Metodologia científica. 6. ed. São Paulo: Pearson, 2007.

CHIAVENATO, I. Empreendedorismo: dando asas ao espírito empreendedor. 4. ed. Barueri: Manole, 2015.

CRESWELL, J. W. Projeto de pesquisa: método qualitativo, quantitativo e misto. 3. ed. Porto Alegre: Bookman, 2010.

DENZIN, N. K.; LINCOLN, Y. S. Strategies of qualitative inquiry. United Kingdom: Sage Publications, 1998.

DORNELAS, J. Empreendedorismo: transformando ideias em negócios. 6. ed. São Paulo: Atlas, 2016.

DRUCKER, P. F. Inovação E espírito empreendedor (entrepreneurship): prática e princí- pio. São Paulo: Cengage Learning, 1985.

GIL, A. C. Como elaborar projetos de pesquisa. 4. ed. São Paulo: Atlas, 2002.

KNIGHT, F. Risk, uncertainty and profit. Chicago: University of Chicago Press, 1921.

LAKATOS, E. M.; MARCONI, M. A. Fundamentos da metodologia científica. 6 . ed. São Paulo: Atlas, 2009.

LAMB, J. C. W.; HAIR, J. J. F.; McDANIEL, C. Marketing. 11. ed. Mason, USA: Cengage Learning, 2011.

QUINTELLA, Paulo Fernando. Entrevista com representante da Districal. Entrevista concedida a Emerson Diego Zotti. Foz do Iguaçu, 1 out. 2016.

ROESCH, S. M. A. Projetos de estágio e de pesquisa em administração. 3 ed. São Paulo: Atlas, 2013.

SARASVATHY, S. D. Causation and effectuation: toward a theoretical shift from economic inevitability to entrepreneurial contingency. The Academy of Management Review, v. 26, n. 2, p. 243-263, $2001 \mathrm{a}$.

What makes entrepreneurs entrepreneurial. Virginia: Darden Business Publishing, $2001 \mathrm{~b}$.

. New venture performance. Virginia: Darden Business Publishing, 2006.

Effectuation: elements of entrepreneurial expertise. [S.1.]: Edward Elgar Publishing Limited, 2008.

The five principles and the effectual cycle. 2011. Disponível em: $<$ http://effectuation.org/sites/default/files/documents/effectuation-3-pager.pdf $>$. Acesso em: 15 jun. 2016.

SARASVATHY, S. D. et al. Three views of entreprenurial opportunity. In: ACS, Z. J.; AU- 
DRETSCH, D. B. Handbook of entrepreneurship research. [S.1.]: Springer US, 2003. p. 141-160.

SEBRAE. Os donos de negócio no Brasil, por regiões e por unidades da federação. Brasília, 2013a. p. 447. Disponível em: <http://www. sebrae.com.br/Sebrae/Portal\%20Sebrae/Anexos/DN_regiao_unidades_federa $\% \mathrm{C} 3 \% \mathrm{~A} 7 \%$ C3\%A3o.pdf>. Acesso em: 6 jun. 2016.

- Sobrevivência das empresas no Brasil coleção estudos e pesquisas. Brasília, 2013b. p. 20. Disponível em: <http://www.sebrae.com.br/Sebrae/Portal\%20Sebrae/Anexos/ Sobrevivencia_das_empresas_no_Brasil=2013.pdf $>$. Acesso em: 6 jun. 2016.

Empresários da indústria, construção, comércio e serviços no Brasil (20032013). Brasília, 2015. p. 11. Disponível em: $<$ http://www.bibliotecas.sebrae.com.br/chronus/ARQUIVOS_CHRONUS/bds/bds.nsf/69e563d410f230c0e5004f1d1998567a/\$File/5454.pdf $>$. Acesso em: 6 jun. 2016.

SEVERINO, A. J. Metodologia do trabalho científico. 23. ed. São Paulo: Cortez, 2013.

SCHUMPETER, J. A. The theory of economic development: an inquiry into profits, capital credit, interest, and the business cycle. Cambridge: Harvard University Press, 1934.

SHANE, S.; VENKATARAMAN, S. The promise of entrepreurship as a field of research. The Academy of Management Review, v. 25, n.1, p. 217-226, 2000.

TRIVIÑOS, A. N. S. Introdução à pesquisa em ciências sociais: a pesquisa qualitativa em educação. São Paulo: Atlas, 1987. 